3

\title{
Temperature Effect on Hydrothermal Liquefaction of Nannochloropsis gaditana and Chlorella sp.
}

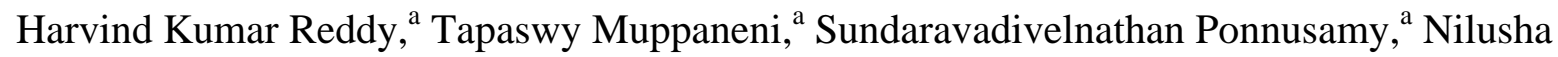 \\ Sudasinghe, ${ }^{\mathrm{b}}$ Ambica Pegallapati, ${ }^{\mathrm{g}}$ Thinesh Selvarathnam, ${ }^{\mathrm{c}}$ Mark Seger, ${ }^{\mathrm{d}}$ Barry Dungan, ${ }^{\mathrm{f}}$ \\ Nagamany Nirmalakhandan, ${ }^{\mathrm{c}}$ Tanner Schaub, ${ }^{\mathrm{b}}$ F. Omar Holguin, ${ }^{\mathrm{f}}$ Peter Lammers, ${ }^{\mathrm{d}}$ Wayne \\ Voorhies, ${ }^{\mathrm{e}}$ and Shuguang Deng ${ }^{\mathrm{a}^{*}}$ \\ Chemical Engineering Department ${ }^{\text {a }}$

$$
\text { Chemical Analysis and Instrumentation Laboratory }{ }^{\text {b }}
$$$$
\text { Civil and Geological Engineering }{ }^{c}
$$$$
\text { Energy Research Laboratory }{ }^{\mathrm{d}}
$$$$
\text { Molecular Biology }{ }^{\text {e }}
$$ \\ Plant and Environmental Sciences ${ }^{\mathrm{f}}$ \\ New Mexico State University \\ Las Cruces, NM 88003, U.S.A.
}

(n)

1

3

4

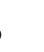

(1)

8

$$
\text { Argonne, IL, 60439, USA. }
$$




\section{Abstract}

Temperature effect on hydrothermal liquefaction (HTL) of Nannochloropsis gaditana

31 and Chlorella sp. was investigated with 10\% biomass loading at HTL temperatures of 180-

$32330^{\circ} \mathrm{C}$, and reaction time of 30 minutes. Maximum yields of $47.5 \%$ for Nannochloropsis sp. and

$33 \quad 32.5 \%$ biocrude oil yields for Chlorella sp. were obtained at $300^{\circ} \mathrm{C}$. The higher heating values of

34 biocrude oils produced in this work ranged between 34 and $39 \mathrm{MJ} / \mathrm{kg}$. $79 \%$ of energy in the

35 Nannochloropsis sp. was recovered at $300^{\circ} \mathrm{C}$ and $62 \%$ of energy recovery from Chlorella sp. was

36 achieved at $200^{\circ} \mathrm{C}$. Valuable nutrients $\left(\mathrm{NH}_{3}-\mathrm{N}\right.$ and $\mathrm{PO}_{4}{ }^{3-)}$ produced during the HTL process were

37 quantified from the aqueous phase for both strains of biomass. The aqueous phase samples

38 obtained at all temperatures were also analyzed for amino acids and carbohydrates. The suitable

39 temperatures for extraction of lipids, amino acids and carbohydrates have been identified.

40 Sequential HTL experiments conducted have shown the prospect of recovering nutrients and

41 other valuable byproducts along with biocrude oil. The experimental results and analysis indicate

42 that sustainable biofuel production requires the development of strain based strategies for the

43 hydrothermal liquefaction process.

44

45

46

47 Key words: Hydrothermal liquefaction, wet algae, sequential extraction and liquefaction, energy recovery, nutrients, by-products 


\section{Introduction}

Algae have received much attention as a source of renewable energy source since 1970s

52 due to depleting fossil fuel sources, unstable global energy markets and environmental issues.

53 The previous generations of biofuels used food crops as feedstock, may not be sustainable and

54 could impose new socio-economic problems in many developing and under developed countries

55 [1]. The algae have highest photosynthesis efficiency compared to other energy plants [2], which

56 grows much faster and produces more biomass. Algae could also be cultivated in wastewater [3,

$574]$ to recover valuable nutrients and to clean various kinds of waste water. Algae are being used

58 as a source of various bio-products like proteins, $\omega$-3 fatty acids, and carbohydrates along with

59 lipids as a feedstock for biofuels [5, 6].

60 In spite of having many advantages over the first two generations of biofuels,

61 commercialization of algal biofuels has not yet been achieved due to a few technical and energy

62 drawbacks. Cultivation and oil extraction of algal biomass have been identified as hurdles for

63 large scale algal biofuel production. Recently, many researchers identified hydrothermal

64 liquefaction as a possible method to extract biocrude oils from algal biomass. Hydrothermal

65 liquefaction's major advantage is the elimination of the drying step completely, which provides

66 several options to extract different compounds/products from algal biomass and whole algae

67 liquefaction [7]. Based on the processing conditions, these processes can be divided as

68 hydrothermal carbonization $\left(150-250^{\circ} \mathrm{C} \&\right.$ less than 20 bar) [8], hydrothermal extraction and

69 liquefaction $\left(200-350^{\circ} \mathrm{C} \& 40-200 \mathrm{bar}\right)$, and hydrothermal gasification (above $350^{\circ} \mathrm{C}$ and 200

70 bar) $[9,10]$. Water's dielectric constant decreases drastically after $200^{\circ} \mathrm{C}$ with an increase in

71 temperature under pressure giving it greater solvating properties. Density also decreases slowly

72 up to the critical pressure point and then drops sharply after the critical pressure. At this point, 
73 the water medium attains gas like densities and liquid like solvent properties. The tendency of

74 providing $\mathrm{H}^{+}$or $\mathrm{OH}^{-}$ions, the ion product $\left(\mathrm{K}_{\mathrm{w}}\right)$ of water, is another important property in

75 performing acid or base catalyzed reactions without any external catalyst depending on

76 temperature and pressure of the water $[7,9,11]$.

Some researchers utilized these properties for selective extraction of desired compounds

78 and for various applications at different processing conditions. Kim et al [12] extracted

79 neutraceutical compounds from citrus pomaces and Ibanez et al., performed extraction of

80 antioxidant compounds from rosemary plants [13]. The selective extraction of lipids from

81 Nannochloropsis salina wet algal biomass using the subcritical water extraction method was

82 demonstrated by Reddy et al. The optimum conditions $\left(220^{\circ} \mathrm{C}\right.$ and $\left.20 \mathrm{~min}\right)$ for extraction of

83 oil/lipids were determined and under these conditions valuable polyunsaturated fatty acids were

84 preserved in algal oil [14]. Some other researchers performed whole algae liquefaction at higher

85 temperatures than the previous work to produce more biocrude oil instead of lipids.

86 Hydrothermal liquefaction of algal biomass was demonstrated by Vardon et al., [15] with

87 Scenedesmus (raw and defatted), and Spirulina strains of biomass; by Reddy et al., with

88 Chlorella sorokiniana and Dunaliella tertiolecta [16] at $300^{\circ} \mathrm{C}$. Valdez et al., studied the

89 hydrothermal liquefaction of Nannochloropsis sp. from $250^{\circ} \mathrm{C}-400^{\circ} \mathrm{C}$ and analyzed each

90 product fraction after liquefaction along with performing energy studies [17]. Influence of

91 external catalyst in the HTL process have shown little or no effect on biocrude oil yield. Among

92 several acid and base catalysts, only $\mathrm{Na}_{2} \mathrm{CO}_{3}$ was able to produce more biocrude yields than the

93 normal HTL media $[18,19]$. A life cycle analysis on HTL of algal biomass reported that better

94 energy return on investment (EROI) and less emissions could be achieved, when compared to

95 cellulosic ethanol production [20]. The bio jet fuel produced from algal biomass cultivated in 
waste water treatment plant could reduce the greenhouse gas emissions by $38-76 \%$ than conventional jet fuel [21]. Recent studies on HTL of algal biomass also showed that the nutrients supplied could be recovered in the water phase after reaction and could be used to

99 cultivate algal biomass with necessary dilutions. Residual water recovered from HTL of Chlorella vulgaris, Scenedesmus dimorphus, Spirulina platensis, and Chlorogloeopsis fritschii was used for cultivation at different dilutions. Near equal or increased growth was observed with residual water of Spirulina platensis and Chlorogloeopsis fritschii species at 400 times dilution.

103 For Chlorella vulgaris, the best growth was achieved with 100 times dilution [22]. Most of the 104 HTL studies on algal biomass have concentrated only on biocrude oil production and performed only at a single or few temperatures. In order to identify a strategy for producing sustainable 106 algal biofuels or algal biorefinery, in this work we studied hydrothermal liquefaction patterns of 107 two species of algal biomass. Nannochloropsis gaditana and Chlorella sp. biomasses at $10 \%$ 108 biomass loading were processed from $180^{\circ} \mathrm{C}$ to $330^{\circ} \mathrm{C}$ for a reaction time of $30 \mathrm{~min}$.. A 109 sequential HTL run was conducted with the bio-char produced at $225^{\circ} \mathrm{C}$ to demonstrate the 110 separation of valuable compounds and lipids. Selective ranges of temperatures for the recovery 111 of lipids, amino acids, carbohydrates and nutrients have been identified. Along with biocrude oil,

112 bio-char and water soluble compounds were also quantified and analyzed after HTL processing.

113 The nutrients presented in HTL residual water were also quantified. Based on the HHVs of 114 biocrude oil and bio-char, the energy recovery calculations were performed.

\section{Experimental section}

\subsection{Materials}

The Nannochloropsis gaditana (CCMP - 1775) culture used in this study was obtained

118 from the Provasoli-Guillard National Center for Culture of Marine Phytoplankton (CCMP). 
119 The Nannochloropsis sp. was grown in the f/2 growth medium, modified to contain $5 \mathrm{mM} \mathrm{NO}_{3}{ }^{-}$

120 and $0.287 \mathrm{mM} \mathrm{PO}_{4}{ }^{3-}$ at a salinity of $20 \mathrm{~g} \mathrm{~L}^{-1}$ in a $4000 \mathrm{~L}$ outdoor Solix photo bioreactor. The

121 algae was grown with $0.8 \% \mathrm{CO}_{2}$ enrichment and maintained at $25^{\circ} \mathrm{C}$ with ambient outdoor

122 lighting. The Chlorella sp. (DOE 1412) culture used in this study was identified by J. Polle

123 (Brooklyn University, N.Y). Chlorella sp. was grown in BG11 growth medium in a 4000 L

124 outdoor Solix photobioreactor. The alga was grown with $0.8 \% \mathrm{CO}_{2}$ enrichment and at $25^{\circ} \mathrm{C}$ and

125 ambient lighting conditions. The algal cultures were harvested using a high speed continuous

126 centrifuge at $18,000 \mathrm{rpm}$ and were stored at $4^{\circ} \mathrm{C}$ until used in the analysis and HTL experiments.

127 The biochemical compositions of both strains of biomass are given in Table 1 . The solvent used

128 in this study was Dichloromethane (DCM) and of analytical grade (Pharmco-aaper).

129

130

131

132

133

134

135

136

137

138

139

140

141

\subsection{Instruments}

A PARR 4593 stainless steel bench top reactor accompanied by a 4843 controller unit manufactured by Parr Instrument Company (Moline, Illinois, USA) was used for conducting hydrothermal extraction and liquefaction experiments. A high pressure reactor manufactured by Supercritical fluid technologies, Inc; (Newark, Delaware, USA) was also used to perform the reaction at $330^{\circ} \mathrm{C}$. Both reactors are equipped with pressure gauges to monitor pressure. A Hewlett Packard 5890 gas chromatograph with a 5972a mass selective detector equipped with a capillary column DB-23, 30m x .25mm diam. x .25 $\mu \mathrm{m}$ film was used for fatty acid methyl ester analysis of biocrude oil. The Leco Pegasus High Throughput Time of Flight Mass Spectrometer (HT TOFMS) with a CTC CombiPAL autosampler was used for qualitative analysis of biocrude oils. Compositional analysis of biocrude oils was performed with a hybrid linear ion trap $7 \mathrm{~T}$ FT-ICR mass spectrometer (LTQ FT, Thermo, San Jose, CA) equipped with an Advion Triversa NanoMate (Advion, Ithaca, NY). Thermo gravimetric analysis (TGA) of wet algal biomass was 
142 performed using a Perkin Elmer Pyris 1 TGA (Perkin Elmer Inc., USA) instrument. The

143 inorganic nutrients were measured using HACH DR6000 spectrophotometer (HACH, Colorado, 144 USA).

145

146

147

148

149

150

151

152

153

154

155

156

157

158

159

160

161

162

163

164

\subsection{FAME (GC-MS) and HTTOF-MS analysis of biocrude oils}

Base catalyzed FAME (fatty acid methyl esters) analysis was performed by direct methylation of dry tissue of biomass and biocrude oils according to [14]. The acid catalyzed FAME analysis was performed with the same experimental procedure by using $0.4 \% \mathrm{H} 2 \mathrm{SO} 4$ and deionized water instead of $\mathrm{NaOH}$ and glacial acetic acid in base catalyzed FAME. In HTTOF MS, the biocrude oil samples were incubated for 5 minutes at $45^{\circ} \mathrm{C}$, and samples were extracted for 5 minutes with a desorb time of 10 minutes for qualitative analysis. A ZB-5ms column (30m x $.25 \mathrm{~mm}$ I.D. $\mathrm{x} .25 \mathrm{um}$ film thickness) was used with helium as the carrier gas at a constant flow rate of $0.6 \mathrm{~mL} /$ minute. The inlet temperature was constant at $225^{\circ} \mathrm{C}$ and the transfer line was $275^{\circ} \mathrm{C}$. The oven ramp started at $35^{\circ} \mathrm{C}$ and held for 4 minutes, then ramped at $5^{\circ} \mathrm{C}$ per minute to $110^{\circ} \mathrm{C}$ with no hold, then ramped at $7^{\circ} \mathrm{C}$ per minute to $280^{\circ} \mathrm{C}$ and held for $0.5 \mathrm{~min}$ for a total run time of 43.78 minutes.

\subsection{Compositional analysis of biocrude oils by FT-ICR MS}

Biocrude oil samples obtained from HTL runs were analyzed by direct infusion electrospray ionization Fourier Transform Ion Cyclotron Resonance mass spectrometry (ESI FT-ICR MS).. HTL bio-oil stock mixtures for both algal strains at each reaction temperature were prepared by dissolving the oil in 1:1 chloroform: methanol to a concentration of $1 \mathrm{mg} / \mathrm{mL}$. Each stock mixture was further diluted to $0.5 \mathrm{mg} / \mathrm{mL}$ in an electrospray ionization solution of 1:2:4 chloroform:methanol:2-propanol containing either $0.1 \%$ formic acid or $0.1 \%$ ammonium hydroxide in positive- and negative-ion modes, respectively [23]. All solvents were high- 
165 performance liquid chromatography (HPLC)-grade and purchased from Sigma-Aldrich (St.

166 Louis, MO). The final diluted samples were centrifuged to remove any suspended particulate

167 matter and FT-ICR mass spectrometry was performed for all oil samples as previously described

168 [24]. Data was collected at a mass resolving power of $\mathrm{m} / \Delta \mathrm{m}_{50 \%}=400,000(\mathrm{~m} / \mathrm{z} 400)$ and a total

169 of 500 and 400 time-domain transients were co-added for each sample in positive- and

170 negative-ion mode, respectively prior to fast Fourier transformation and frequency to $\mathrm{m} / \mathrm{z}$

171 conversion.. Mass spectra were internally calibrated and elemental compositions were assigned

172 to the observed ions in each mass spectrum. A variety of non-lipid constituent molecules of HTL

173 biocrude oil were identified by their heteroatom class. Residual lipids in the oil were identified

174 by matching the assigned elemental compositions to an in-house assembled lipid database

175 derived from Lipid Maps (Nature, Lipidomics Gateway) as previously described[25].

176 2.5. Amino acids quantification and carbohydrate profiling

Amino acids were separated from the aqueous HTL fraction by strong cation exchange

178 on a Supel Select SCX SPE $30 \mathrm{mg} / 1.0 \mathrm{~mL}$ SPE Tube (Supleco, Bellefonte, PA). The SPE

179 columns were conditioned with two volumes of $0.1 \mathrm{~N} \mathrm{HCl}$. A $2.0 \mathrm{~mL}$ aliquot of the aqueous

180 fraction was acidified (to $0.1 \mathrm{~N} \mathrm{HCl}$ ) by the addition of $34 \mu \mathrm{L}$ of $6.0 \mathrm{~N} \mathrm{HCl}$ and then passed

181 through the SPE Column. The column was washed with two volumes of $0.1 \mathrm{~N} \mathrm{HCl}$ and the

182 bound amino acids were eluted with two volumes of $\mathrm{NH}_{4} \mathrm{OH}$. A total of $200 \mu \mathrm{L}$ of $2.5 \mathrm{mM}$

183 norleucine solution was added as an internal standard to the eluted extracts before they were

184 completely dried in glass vials by a speedvac (Eppendorf, Hauppauge, NY). The dried residue

185 was resuspended in $100 \mu \mathrm{L}$ of pyridine and subsequently derivatized by the addition of $100 \mu \mathrm{L}$

186 N-tert-Butyldimethylsilyl-N-methyltrifluoroacetamide (MTBSTFA; Sigma, St. Louis, MO) and

187 incubated at $110^{\circ} \mathrm{C}$ for 1 hour. The resulting silylated derivatives were chromatographed on a 
Varian 3800 GC coupled to a Saturn 2000R scanning from 40-450 m/z with a 12 min filament delay. Samples were injected by splitless injection, and the MS temperatures were set as follows: inlet and transfer line were held at $250^{\circ} \mathrm{C}$, trap $150^{\circ} \mathrm{C}$, manifold $35^{\circ} \mathrm{C}$. Separation was achieved with a temperature program of $80^{\circ} \mathrm{C}$ for $2 \mathrm{~min}$, then ramped at $4{ }^{\circ} \mathrm{C} \min ^{-1}$ to $250^{\circ} \mathrm{C}$ on a $30 \mathrm{~m}$ ZB-5 column $0.25 \mathrm{~mm}$ ID, $0.25 \mu \mathrm{m}$ film thickness (Phenomenex, Torrance, CA ) at a constant flow of $1.0 \mathrm{~mL} \mathrm{~min}^{-1}$. Internal standard quantification was performed by relative response factors of Norleucine to amino acid mix cat \# A6407 (Sigma, St. Louis, MO).

The carbohydrate profiling of the aqueous HTL fraction was adapted from the method described by Broeckling et al., 2004 using $0.2 \mathrm{~mL}$ of evaporated aqueous residue[26]. All samples were analyzed using a Varian 3800 GC coupled to a Saturn 2000R scanning from 45$550 \mathrm{~m} / \mathrm{z}$ with a $10 \mathrm{~min}$ filament delay. Samples were injected at a 20:1 split ratio, and the MS temperatures were set as follows: inlet and transfer line were held at $250^{\circ} \mathrm{C}$, trap $150^{\circ} \mathrm{C}$, manifold $35^{\circ} \mathrm{C}$. Separation was achieved with a temperature program of $70^{\circ} \mathrm{C}$ for 1 min, then ramped at $3^{\circ} \mathrm{C} \min ^{-1}$ to $330^{\circ} \mathrm{C}$ on a $30 \mathrm{~m}$ ZB-5 column $0.25 \mathrm{~mm}$ ID, $0.25 \mu \mathrm{m}$ film thickness (Phenomenex, Torrance, Ca) at a constant flow of $1.0 \mathrm{~mL} \mathrm{~min}{ }^{-1}$. The resulting peaks were identified by matching to the NIST mass spectral database.

\subsection{Experimental procedures}

Biomass with $10 \%$ biomass loading ( $\mathrm{w} / \mathrm{v})$ was prepared by adding the proper amount of supernatant water collected after harvesting. $50 \mathrm{~mL}$ of this slurry was fed to the reactor, and nitrogen was purged three times to dispose of any air in the reactor. 200 psi of initial pressure was maintained to control the rapid boiling of water. Subsequently, the reactor was heated according to the experimental plan by using the controller unit and held for $30 \mathrm{~min}$, and the pressure was recorded at target temperature. The recorded pressures at each experimental run 
211 were presented in supplementary information Table S5. The reactor was cooled down to room

212 temperature by means of an external fan before adding $30 \mathrm{~mL}$ of Dichloromethane (DCM) to

213 separate biocrude oil from the product mixture. The DCM mixture was transferred to a 214 separation funnel through a filter paper and allowed to stand for 15 minutes for phase separation.

215 The collected bio-char was separated, dried and quantified for the material and energy 216 calculations. The denser DCM phase, which includes biocrude oil, settled at the bottom and the 217 residual water comprised the less dense upper phase. HTL product was recovered from the 218 separated DCM phase by a rotary evaporator to yield biocrude oil (B.C.O) at $65^{\circ} \mathrm{C}$ under vacuum 219 (94-96\% recovery). Weight of the biocrude oil was noted carefully, and each experimental run 220 was performed three times. The weight of water soluble compounds (W.S.C) was also measured 221 gravimetrically. Biocrude oil samples and residual water samples were stored at $-5^{\circ} \mathrm{C}$ for further 222 analysis. Yields of biocrude oil, bio-char (B.Ch), and water soluble compounds were calculated 223 based on the following equations. The remaining mass fraction was considered as gaseous 224 products.

$$
\begin{aligned}
& \text { Biocrude oil yield }(\%)=\frac{\text { weight of biocrude oil }}{\text { dry weight of biomass }} * 100 \\
& \text { Bio - char yield }(\%)=\frac{\text { weight of bio }- \text { char }}{\text { dry weight of biomass }} * 100 \\
& \text { Yield of W.S.C }(\%)=\frac{\text { weight of W.S.C }}{\text { dry weight of biomass }} * 100
\end{aligned}
$$

225 The high heating values (H.H.V) of biocrude oil, and bio-char were determined with a micro 226 bomb calorimeter. These determined H.H.V numbers were used to calculate energy recovery 227 calculations. Energy recovery and consumption ratios were calculated based on the following 228 equations on dry weight basis. 
Energy recovery \% (ER)

$$
\begin{gathered}
=\frac{(\text { Wt. of B. C. O } * \text { HHV of B. C. O })+(\text { Wt. of B. Ch } * \text { HHV of B. Ch })}{(\text { Wt. of algal biomass } * \text { HHV of algal biomass })} * 100 \\
\text { Energy consumption ratio }(\mathrm{ECR})=\frac{\text { Energy consumed for HTL process }}{\text { Energy available in biocrude oil }}
\end{gathered}
$$

\section{Energy available in biocrude oil $=\mathrm{Wt}$. of biocrude oil $* \mathrm{HHV}$ of biocrude oil}

229 The amount of energy consumed in the HTL process was calculated using $1.31 \mathrm{~kJ} / \mathrm{kg} . \mathrm{K}$ as

230 specific heat for algal biomass [27]. The energy recovery from HTL process was taken as 50\%

231 though heat recovery and the ECR was calculated with and without heat recovery.

\section{3. Results and discussion}

\section{3.1. Influence of temperature on HTL products}

Major product fractions identified during this work were biocrude oil, water soluble compounds (W.S.C), bio-char or solid residue and gaseous product (calculated by difference

236 with losses during experiments). Yields of the above mentioned products obtained from

237 hydrothermal processing of both Nannochloropsis sp. and Chlorella sp. are presented in Figure 1 238 on the dry weight basis. Increase in temperature improved the biocrude oil yield for both strains

239 of biomass, but followed a different pattern. In the case of Nannochloropsis sp., yield of

240 biocrude oil was increased from $16.85 \%$ at $180^{\circ} \mathrm{C}$ and stabilized at $25 \%$ between $225^{\circ} \mathrm{C}$ and

$241250^{\circ} \mathrm{C}$. A slight increase of biocrude oil yield was observed at $275^{\circ} \mathrm{C}$ than the previous

242 temperature, but at $300^{\circ} \mathrm{C}$ drastic increase in yield was achieved recording $47.5 \%$. Further

243 increase in temperature resulted in reduction of biocrude oil yield due to higher gasification.

244 Larger amounts of gases were formed above $275^{\circ} \mathrm{C}$, where $31 \%$ of the biomass was converted to 245 gaseous product at $330^{\circ} \mathrm{C}$ due to rapid gasification. 
Reaction temperature is the major influencing factor that affects the production of

247 biocrude oil and its properties, and varies the polarity of the water [7, 28]. A similar pattern of

248 biocrude oil yield was observed from the Chlorella sp., but the amount of biocrude oil produced

249 was low over the range of all temperatures when compared to Nannochloropsis biomass. This

250 difference can primarily be attributed to the lower lipid content of the biomass. Despite having

251 lower lipids, a maximum of $32.54 \%$ of yield was achieved at $300^{\circ} \mathrm{C}$ and a further increase in

252 temperature slightly reduced the yield. Interestingly, more gaseous product was observed from

$253180^{\circ} \mathrm{C}$ and above for Chlorella sp. biomass. $15.5 \%$ of gaseous product was observed at $180^{\circ} \mathrm{C}$

254 and reached a maximum of $52.24 \%$ at $330^{\circ} \mathrm{C}$. In the case of both strains more biocrude oil was

255 generated due to an increase in temperature, where the ionic product $\left(\mathrm{K}_{\mathrm{w}}=\left[\mathrm{H}^{+}\right]\left[\mathrm{OH}^{-}\right]\right)$of water

256 increases. Higher ionic product of water provides more $\mathrm{H}^{+}$and $\mathrm{OH}^{-}$ions, which drives the

257 hydrothermal cleavage of biochemical compounds present in the biomass into smaller

258 compounds. Hydrothermal liquefaction of Nannochloropsis salina and Spirulina platensis

259 reported much higher biocrude production than their original lipid content. $47 \%$ of biocrude oil

260 yields for Nannochloropsis sp. at $350^{\circ} \mathrm{C}$ and $38 \%$ for Spirulina sp. at $310^{\circ} \mathrm{C}$ were reported [29].

261 Depending upon reaction conditions, condensation and repolymerization reactions influence the

262 formation of biocrude oil [7, 30].

263 As shown in Figure 1, water soluble compounds (W.S.C) were observed to form

264 beginning from lower temperatures with Nannochloropsis sp. and Chlorellasp.. In the case of

265 Nannochloropsis sp., the amount of W.S.C was increased up to $250^{\circ} \mathrm{C}$, where a maximum of

$26627 \%$ W.S.C were observed. Further increase in temperature caused repolymerization of these

267 water soluble compounds, which might have been converted to either biocrude oil or gaseous

268 products. In the case of Chlorella sp., W.S.C's were increased up to $225^{\circ} \mathrm{C}$, where a maximum of 
24.06\% were recovered. Further increase in temperature caused repolymerization or condensation of these compounds into biocrude oil or gaseous phase. Their weight fraction was drastically reduced at higher temperatures. The yield of W.S.Cs reached 3.85\% for Chlorella sp. and $10.50 \%$ for Nannochloropsis sp. at $330^{\circ} \mathrm{C}$. High amounts of ash content present in the biomass may also have contributed to this high W.S.C. in the case of Nannochloropsis sp. Water soluble compounds produced at lower temperatures from proteins and carbohydrate compounds were repolymerized at higher temperature, which also contributed to the increase in yield of biocrude oil and this trend was observed with both strains of biomass. A similar pattern was previously reported, where conversion of water soluble compounds into bio-oil at higher temperatures was observed [31, 32].

The subsequent important product is bio-char, which decreased from $62 \%$ at $180^{\circ} \mathrm{C}$ to $16.5 \%$ at $330^{\circ} \mathrm{C}$ for Nannochloropsis sp.. At 300 and $330^{\circ} \mathrm{C}$, drastic reductions in mass of biochar were observed due to disintegration of algae cells and conversion of metabolites into biocrude oil and gaseous products. Trends of bio-char yield of Chlorella sp., were also similar to the former strains trends, and major weight reductions occurred between $200-250^{\circ} \mathrm{C}$. Yield of bio-char is reduced from $55.2 \%$ to $13.35 \%$ at $330^{\circ} \mathrm{C}$. In this study, we identified bio-char as one of the crucial products which improves the overall energetics of the process and provides options for other applications. Along with changes in weight fractions of bio-char, its heating values were also varied. This indicates the extraction and liquefaction of biochemical compounds present in the algal biomass. Yu et al., have reported that bio-char or solid residue yield was decreased with an increase in temperature. A rapid reduction in bio-char was observed between 0 to 30 min. and compared to a slow decrease from 30 to 120 min., as most of the compounds converted into bio-oil or into other phases [33]. 


\subsection{Analysis of biocrude oils}

The biocrude oils were analyzed thoroughly for their chemical, thermal properties and calorific value over the range of all temperatures. The primary constituents of the biocrude oil at a lower temperature were lipids and their contribution to the yield of biocrude oil was different in both strains of biomass. In the case of Nannochloropsis sp., the amount of lipids presented in the biocrude oil increased with temperature up to $300^{\circ} \mathrm{C}$. But a greater variation in their chemical form was observed, as a majority of the lipids were converted into free fatty acids (FFA) from $225^{\circ} \mathrm{C}$ and upwards. This was due to hydrolysis of lipids above $200^{\circ} \mathrm{C}$, and formation of FFAs is shown in Figure 2. Up to $275^{\circ} \mathrm{C}$, half or more than $50 \%$ of the biocrude oil was formed by lipids. At $300^{\circ} \mathrm{C}, 43.5 \%$ of the biocrude oil was from lipids and it was $\sim 84 \%$ of the total lipid content of the biomass. At lower temperatures membrane constituents like phytol, 2-phytene, minor quantities of alkanes, nitrogen containing amides and many other minute compounds were observed in the remaining portion of biocrude oil. The high throughput mass spectrometer detected as low as 180 compounds at lowest temperature to 1300 compounds at highest temperature. At higher temperatures the larger compounds like proteins, lipids, and cellulosic compounds defragmented to form smaller compounds. Due to wide variety of possible reactions (hydrolysis, dehydration, decarboxylation, deamination, repolymerization, isomerization etc.,) in the hydrothermal liquefaction process, different classes of $\mathrm{N}, \mathrm{O}$, and $\mathrm{S}$ containing compounds were formed at increasing temperatures. These compounds were observed in both FT-ICR MS and HT TOF MS analyses.

Above $225^{\circ} \mathrm{C}$, most of the membrane associated compounds started degrading and disappeared completely at higher temperatures. As temperatures increased above $250^{\circ} \mathrm{C}$, the contribution of lipids to biocrude oils decreased primarily due to contribution from other 
315 biochemical compounds like proteins and carbohydrates. This phenomenon was also confirmed by the FT-ICR MS analysis.

. For the positive-ion mode, distribution of non-lipid compounds $\left(\mathrm{N}_{1-3} \mathrm{O}_{1-3}\right)$ in the

318 biocrude oils and their variation in the abundance with reaction temperature are very similar for

319 both algal strains. Primary lipids observed for N. gaditana low-temperature $\left(<250{ }^{\circ} \mathrm{C}\right)$ oil in the

320 positive-ion ESI FT-ICR MS are acylglycerols. Major compounds observed in the negative ion

321 mode include free fatty acids regardless of reaction temperature. A more detailed description of

322 the compositional analysis of the biocrude oils has been reported by Sudasinghe et al.[24].

Unlike the biocrude oil produced from Nannochloropsis sp., biocrude oil produced from

324 chlorella sp,.has shown different chemical properties and this difference can be attributed to their

325 respective biochemical composition. A maximum of $43 \%$ of the lipids was observed at $200^{\circ} \mathrm{C}$ in

326 biocrude, which was the highest contribution of lipids to biocrude over the range of

327 temperatures. Hydrolysis was observed right from $180^{\circ} \mathrm{C}$ and reached highest at $200^{\circ} \mathrm{C}$, where

$32876 \%$ of the lipids extracted were in the form of FFA. Interestingly, as shown in Figure 2 these

329 FFA compounds started degrading above $200^{\circ} \mathrm{C}$. The membrane alcohols like phytol, isophytol,

330 and other minor compounds were detected below $225^{\circ} \mathrm{C}$, and most of these compounds were

331 degraded above $225^{\circ} \mathrm{C}$ and formed different compounds similar to the previous case. The

332 difference in hydrolysis of lipids in both these strains could be due to a higher proportion of

333 unsaturated fatty acids present in Chlorella sp., which are very sensitive to high temperatures. In

334 both cases of biomass $65-70 \%$ of the neutral lipids were extracted at $225^{\circ} \mathrm{C}$ into the biocrude oil.

335 Positive-ion ESI FT-ICR MS analysis indicates that low temperature $\left(<225^{\circ} \mathrm{C}\right)$ Chlorella sp.

336 biocrude oil is primarily comprised of betaine lipids. Similar to N. gaditana, acidic compounds 
337 observed for Chlorella sp. oil in the negative ion mode are dominated by free fatty acids for all 338 reaction temperatures..

In both cases of biomass many valuable compounds have been extracted into biocrude oil, providing a possible commercial application of hydrothermal extraction. Biocrude oil

341 produced from Nannochloropsis sp., at lower temperatures $\left(225^{\circ} \mathrm{C}\right)$ preserved valuable

342 polyunsaturated fatty acids. They are Arachidonic acid (C20:4n6 - 4\% of lipids),

343 Eicosapentaenoic acid (C20: 5n3-3\% lipids), and membrane alcohols like phytol (3\% based on

344 peak area-not quantified). Chlorella sp., has more membrane compounds than the previous 345 strain, they are isophytol (16.28\%), and phytol (7.5\%) based on peak area (not quantified) at $346200^{\circ} \mathrm{C}$, which also have commercial value. Compound identity is confirmed by fragment ion 347 mass spectra provided by electron impaction ionization. These compounds are also thermo labile, 348 which were degraded from $225^{\circ} \mathrm{C}$ and above.

As shown in Figure S1, the TGA curves of biocrude oils shows increasing presence of 350 volatile compounds with increasing HTL processing temperatures. The biocrude oils produced 351 from Nannochloropsis sp., have showed this phenomenon. The biocrude oils produced with 352 Chlorella sp., have minor differences in their TGA curves, and this is due to less lipids or 353 contribution of protein based compounds than Nannochloropsis sp. The biocrude oil produced at 354 the maximum yield point $\left(300^{\circ} \mathrm{C}\right)$ has showed the same thermal behavior. When compared to 355 distillation curve of Ural crude oil [34], the distillation curves of the biocrude oils produced at $356300^{\circ} \mathrm{C}$ are very near to distillation curve of diesel (shown in Figure S2). This shows that the 357 biocrude oils produced from algal biomass could be used as feedstock to produce transportation 358 fuels with necessary denitrification and deoxygenation prior to the refining. 


\subsection{Analysis of water soluble compounds}

Water soluble compounds are valuable products after biocrude oils, as they consists valuable nutrients, byproducts like amino acids and carbohydrates. The residual water was analyzed in two phases, one for quantification of nutrients and the other for water soluble organic compounds.

HTL water samples were analyzed for ammoniacal nitrogen $\left(\mathrm{NH}_{3}-\mathrm{N}\right)$ and Phosphate

$\left(\mathrm{PO}_{4}{ }^{3-}\right)$ according to Selvaratnam et al. [35]. In both cases of biomass, the ammoniacal nitrogen recovery was detected at different concentrations at each temperature. In both cases, the total nitrogen (TN) increased slightly at lower temperatures up to $250^{\circ} \mathrm{C}$ and stabilized at higher temperatures. Total nitrogen quantities varied greatly for both strains due to their biochemical composition. The highest total nitrogen detected was $5808 \mathrm{ppm}$ at $250^{\circ} \mathrm{C}$ for Chlorella sp., and 1761 ppm for Nannochloropsis sp. at $225^{\circ} \mathrm{C}$. For both strains of biomass, the amount of $\mathrm{NH}_{3}-\mathrm{N}$

371 increased with an increase in processing temperature and was found to be highest at $300^{\circ} \mathrm{C}$. The

372 highest being 820 ppm with Nannochloropsis sp. and 2475 ppm of $\mathrm{NH}_{3}-\mathrm{N}$ with chlorella

373 biomass were obtained (Figure 3a). Proteins present in the biomass decompose into water soluble

374 amino acids and ammonia [17], and the concentration of these compounds varied with

375 processing temperature. Ammonium was formed by deamination of amino acids, which are 376 produced due to hydrolysis of proteins [22]. The difference in $\mathrm{TN}$ and $\mathrm{NH}_{3}-\mathrm{N}$ for both cases of

377 biomass at the same temperature was due to variation in biochemical composition and less 378 protein content in Nannochloropsis sp. A larger contribution of proteins to the biocrude oil with 379 the chlorella biomass is observed, also contributed to more $\mathrm{TN}$ and $\mathrm{NH}_{3}-\mathrm{N}$ in water phase. 380 Another valuable nutrient quantified was phosphate $\left(\mathrm{PO}_{4}{ }^{3-}\right)$. As shown in Figure 3b, in both 381 cases of biomass the amount of phosphate increased with increase in temperature up to $200^{\circ} \mathrm{C}$ 
382 then decreased as temperature increased above $200^{\circ} \mathrm{C}$. The highest phosphate concentration of 383280 ppm with Nannochloropsis sp. and 26 ppm with Chlorella sp. at $200^{\circ} \mathrm{C}$ were found. Anyhow 384 for the recycling of these nutrients, analysis of organic compounds also needed to be conducted 385 as phenolic compounds present in the water may inhibit the growth of algal biomass. After 386 appropriate dilutions of the water fraction, it was used successfully to grow algal biomass [22]. HTL aqueous phase was analyzed as a source of recyclable soluble organic compounds. The amino acids are one of the valuable compounds being produced due to hydrolysis of protein 389 at lower temperatures. In Table S1 and S2, most abundant and quantified amino acids are 390 presented. The highest concentrations of amino acids at 1.9 and $1.92 \mathrm{nmol} / \mathrm{mL}$ were observed 391 for Nannochloropsis sp. and Chlorella sp. respectively at $200^{\circ} \mathrm{C}$. The mol\% of simple amino acid 392 glycine was increased with ascending processing temperatures as the remaining amino acids 393 were degraded continuously with the increasing temperatures. This degradation of amino acids 394 with increasing temperatures may have contributed to the increase of $\mathrm{NH}_{3}-\mathrm{N}$ at higher 395 temperatures. The deamination and decarboxylation reactions cause the degradation of amino 396 acids forming pyrolyzed compounds and gaseous compounds at higher temperatures [36]. These 397 results also suggest the need to track peptides which are intermediate compounds between 398 proteins and amino acids, which will provide more understanding of protein behavior in the 399 complex HTL reaction medium.

Along with amino acid analysis, exploratory runs were conducted to detect the presence 401 of carbohydrates and other compounds. This analysis revealed the presence of large amounts of 402 sugars (including mono, di and polysaccharides), sugar alcohols, glycerol and nitrogen

403 containing compounds. A ratio of the abundance of the compounds at the higher temperature and 404 lowest temperature $\left(180^{\circ} \mathrm{C}\right)$ indicates that each compound exhibits independent behavior with 
increasing temperature (Shown in Table S3 and S4). Both strains of biomass have only a few common and far more different compounds due to their biochemical composition. But interestingly both strains of biomass have compounds like sugars (glucose, melezitose, galactose), sugar alcohols (mannitol, galactitol, sorbitol) and many unidentified carbohydrates. In both cases highest concentrations of these carbohydrates were found at $250^{\circ} \mathrm{C}$ and below (Figure 4). As discussed in the biocrude oil analysis section, due to hydrolysis of lipids abundance of glycerol started increasing with increasing temperature up to $300^{\circ} \mathrm{C}$ and started degrading above $300^{\circ} \mathrm{C}$. The above mentioned sugar alcohols have commercial pharmaceutical applications and needed to be quantified. The original GC-MS spectra have identified 180-200 compounds, but with very low abundance. For quantification of the highly abundant and valuable compounds separate quantification methods have to be used for the individual class of compounds.

\subsection{Higher heating values (HHV) and energy recovery}

The Higher heating values (HHV) of biocrude oils and bio-char were determined with a micro-bomb calorimeter. Results of the HHV of biocrude oils and bio-char are presented in Table 2. Higher values of HHV were observed for biocrude oils produced at lower temperatures. In the case of Nannochloropsis sp., HHVs of biocrude oils started decreasing at $250^{\circ} \mathrm{C}$ and continued decreasing as temperature increased, reaching a minimum at $300^{\circ} \mathrm{C}$. This reducing behavior could be attributed to the presence of more nitrogenous compounds with increase in temperature above $250^{\circ} \mathrm{C}$ as observed in FT-ICR, HT TOFMS analysis. Further increase in temperature increased the energy content again, due to deoxygenation of biocrude oils. Similar observation was reported by Valdez et al., where reduction in oxygen content improved the HHV of the biocrude oil [17]. A similar trend of HHV variation was observed with Chlorella sp., where higher HHVs were observed when compared to biocrude oils produced at high 
428 temperature. When compared to HHVs of biocrude oils produced with Nannochloropsis sp., the

429 HHVs of biocrude oils produced with Chlorella sp. were slightly lower due to the presence of

430 nitrogenous compounds from the $180^{\circ} \mathrm{C}$. As temperature increased above $275^{\circ} \mathrm{C}$, the $\mathrm{HHV}$ of the

431 biocrude oils was increased due to deoxygenation at high temperatures. Alba et al., also have

432 observed similar behavior of increase in nitrogen and decrease in oxygen content in biocrude

433 oils, which influences the HHV of the biocrude oils [32]. The bio-char recovered after

434 liquefaction also has considerable energy value associated with it. In both cases of biomass, at

435 lower temperatures the HHVs for these char samples have energy content between 18-20 MJ/Kg.

436 In the case of Chlorellasp., above $250^{\circ} \mathrm{C}$ lower HHVs were observed as most of the energy dense

437 compounds were converted into other product fractions. Similar observations were recorded with

438 bio-char samples obtained above $275^{\circ} \mathrm{C}$ with Nannochloropsis sp. The energy recovery from the

439 biomass was calculated based on the HHVs measured.

$440 \quad$ Energy recovery (\%) was calculated based on HHVs of biocrude oil, bio-char and feed

441 biomass. The highest energy recovery of $78 \%$ was achieved with Nannochloropsis sp. at $300^{\circ} \mathrm{C}$.

442 Above $70 \%$ of energy recovery was attained at all temperatures except at $330^{\circ} \mathrm{C}$ due to

443 gasification of biomass, reduced contribution of biocrude oil and bio-char. In the case of

444 Chlorella sp., only $61.3 \%$ of the energy was recovered at $200^{\circ} \mathrm{C}$ and the energy recovery was

445 decreased with increase in temperature. Reasons for lower energy recoveries for Chlorella

446 biomass were lower lipid based energy, and more gasification. The ECR numbers shows that

447 most of the experimental runs are energy positive except very few even only with biocrude oil as

448 the product. When heat recovery is employed the energy consumption is much reduced making

449 HTL as an attractive option for biofuel production. The lowest energy consuming temperature or 
ECR (0.41 for Nannochloropsis sp., and 0.54 for Chlorella sp.) is observed at $300^{\circ} \mathrm{C}$ for both strains of biomass due to highest production of biocrude oil at that temperature.

\subsection{Sequential HTL (SE-HTL) and byproducts}

To investigate the possibility of an algal biorefinery, we have conducted sequential HTL runs with bio-char of Nannochloropsis sp. obtained at $225^{\circ} \mathrm{C}$. Triplicate experiments at $300^{\circ} \mathrm{C}$ with D.I water as media were conducted. The results showed a slight decrease in cumulative biocrude yield $\left(25.6\left(225^{\circ} \mathrm{C}\right)+16.52\left(\mathrm{SE} \mathrm{HTL}-300^{\circ} \mathrm{C}\right)=42.12 \%\right.$. The HHV of the biocrude oil was found to be $39.14 \pm 0.66 \mathrm{MJ} / \mathrm{Kg}$. This decrease in yield of biocrude oil was due to separation of water soluble compounds at $225^{\circ} \mathrm{C}$. Because of the separation of nitrogen in the water phase at lower temperatures may have resulted in improved HHV of the biocrude [18]. These experimental results indicate the possibility of separating nutrients, valuable water soluble organic compounds, preservation of temperature sensitive compounds at lower temperatures, and conversion of remaining biomass into biocrude oil. Similarly, the bio-char obtained from Chlorella sp. processed at $200^{\circ} \mathrm{C}$ contains high amounts of crude protein. This high protein content makes it a good animal feed source or the recoverable protein can be extracted for commercial human food applications as per demand. The bio-char can also be fired along with coal in power generation because of its higher calorific values. The gasification of the bio-char could be used to make syngas, which can be further converted into valuable industrial chemical products [37]. Other possible applications for bio-char are water purification [38] and soil remediation [39]. It has been reported that the production of biogas through anaerobic digestion of lipid extracted algae after lipid extraction could reduce the energy consumption from 56.9 $\mathrm{MJ} / \mathrm{kg}$ to $46.0 \mathrm{MJ} / \mathrm{kg}$ to produce $1 \mathrm{~kg}$ biodiesel [27]. The utilization of this char for other energy byproducts development produces more energy and provides more alternatives for the algal 
473 biofuels sustainability. But, the final path of processing strategies and product identification

474 could only be possible after extensive life cycle and techno economic assessments for individual

475 strains of biomass.

\section{4. Conclusions}

477

Hydrothermal extraction and liquefaction experiments were conducted with two strains of 478 algal biomass having different biochemical composition. The experimental results indicate that 479 biocrude oil could be produced from proteins and carbohydrates along with lipid content present 480 in the biomass. The highest biocrude oil yield of $47.5 \%$ was observed at $300^{\circ} \mathrm{C}$ for 481 Nannochloropsis sp. and $32.5 \%$ for Chlorella sp. at $275^{\circ} \mathrm{C}$. The HHV of biocrude oil ranged 482 between 34-39 MJ/Kg. The bio-char also has 8-21 MJ/Kg of HHV depending upon the 483 processing temperature. The analysis of the water fraction shows the recovery of valuable 484 nutrients like $\mathrm{NH}_{3}-\mathrm{N}$ and $\mathrm{PO}_{4}{ }^{3-}$, which reduces nutrient costs in cultivation. The water soluble 485 compounds like amino acids, sugars, sugar alcohols, and glycerol provide possible profitable 486 byproducts. The SE-HTL experiments show the possibility of an algal biorefinery with 487 hydrothermal extraction and liquefaction methods to produce fuels, valuable nutrients for 488 humans and algae as byproducts.

489

490 Acknowledgements

491 This project was partially supported by US Department of Energy (DE-EE0003046, DE492 EE0006316) and National Science Foundation (EEC-1028968, IIA-1301346). 
[1] Demirbas A, Fatih Demirbas M. Importance of algae oil as a source of biodiesel. Energy Convers Manage. 2011;52:163-70. Biofuels: High-Efficiency Microalgae for Biodiesel Production. Bioenergy Research. 2008;1:20-43. [3] Wang M, Kuo-Dahab WC, Dolan S, Park C. Kinetics of nutrient removal and expression of extracellular polymeric substances of the microalgae, Chlorella sp. and Micractinium sp., in wastewater treatment. Bioresource Technology. 2014;154:131-7.

[4] Rawat I, Kumar RR, Mutanda T, Bux F. Dual role of microalgae: Phycoremediation of domestic wastewater and biomass production for sustainable biofuels production. Appl Energy. 2011;88:3411-24. [5] Wijffels RH, Barbosa MJ, Eppink MHM. Microalgae for the production of bulk chemicals and biofuels. Biofuels Bioproducts \& Biorefining-Biofpr. 2010;4:287-95. [7] Savage PE. A perspective on catalysis in sub- and supercritical water. J Supercritical Fluids. 2009;47:407-14. carbonization of microalgae. Biomass \& Bioenergy. 2010;34:875-82.

[9] Peterson AA, Vogel F, Lachance RP, Froeling M, Antal MJ, Jr., Tester JW. Thermochemical biofuel production in hydrothermal media: A review of sub- and supercritical water technologies. Energy \& Environmental Science. 2008;1:32-65.

[10] Moeller M, Nilges P, Harnisch F, Schroeder U. Subcritical Water as Reaction Environment: Fundamentals of Hydrothermal Biomass Transformation. Chemsuschem. 2011;4:566-79.

[11] Akiya N, Savage PE. Roles of water for chemical reactions in high-temperature water. Chemical Reviews. 2002;102:2725-50.

[12] Kim J-W, Nagaoka T, Ishida Y, Hasegawa T, Kitagawa K, Lee S-C. Subcritical Water Extraction of Nutraceutical Compounds from Citrus Pomaces. Separation Science and Technology. 2009;44:2598-608. [13] Ibanez E, Kubatova A, Senorans FJ, Cavero S, Reglero G, Hawthorne SB. Subcritical water extraction of antioxidant compounds from rosemary plants. Journal of Agricultural and Food Chemistry. 2003;51:375-82.

[14] Reddy HK, Muppaneni T, Sun Y, Li Y, Ponnusamy S, Patil PD, et al. Subcritical water extraction of lipids from wet algae for biodiesel production. Fuel. 2014;133:73-81.

[15] Vardon DR, Sharma BK, Blazina GV, Rajagopalan K, Strathmann TJ. Thermochemical conversion of raw and defatted algal biomass via hydrothermal liquefaction and slow pyrolysis. Bioresource Technology. 2012;109:178-87.

[16] Reddy HK, Muppaneni T, Rastegary J, Shirazi SA, Ghassemi A, Deng SG. ASI: Hydrothermal Extraction and Characterization of Bio-Crude Oils from Wet Chlorella Sorokiniana and Dunaliella Tertiolecta. Environ Prog Sustain. 2013;32:910-5.

[17] Valdez PJ, Nelson MC, Wang HY, Lin XN, Savage PE. Hydrothermal liquefaction of Nannochloropsis sp.: Systematic study of process variables and analysis of the product fractions. Biomass and Bioenergy. 2012;46:317-31.

[18] Biller $P$, Ross AB. Potential yields and properties of oil from the hydrothermal liquefaction of microalgae with different biochemical content. Bioresource Technology. 2011;102.

540 the thermochemical liquefaction of microalga Spirulina platensis. Appl Energy. 2012;98:368-75. 
[20] Liu X, Saydah B, Eranki P, Colosi LM, Greg Mitchell B, Rhodes J, et al. Pilot-scale data provide enhanced estimates of the life cycle energy and emissions profile of algae biofuels produced via hydrothermal liquefaction. Bioresource Technology. 2013;148:163-71.

[21] Fortier MOP, Roberts GW, Stagg-Williams SM, Sturm BSM. Life cycle assessment of bio-jet fuel from hydrothermal liquefaction of microalgae. Appl Energy. 2014;122:73-82.

[22] Biller P, Ross AB, Skill SC, Lea-Langton A, Balasundaram B, Hall C, et al. Nutrient recycling of aqueous phase for microalgae cultivation from the hydrothermal liquefaction process. Algal Research. 2012;1:706.

[23] Sudasinghe N, Dungan B, Lammers P, Albrecht K, Elliott D, Hallen R, et al. High resolution FT-ICR mass spectral analysis of bio-oil and residual water soluble organics produced by hydrothermal liquefaction of the marine microalga Nannochloropsis salina. Fuel. 2014;119:47-56. [24] Sudasinghe N, Reddy H, Csakan N, Deng S, Lammers P, Schaub T. Temperature-Dependent Lipid Conversion and Nonlipid Composition of Microalgal Hydrothermal Liquefaction Oils Monitored by Fourier Transform Ion Cyclotron Resonance Mass Spectrometry. BioEnergy Research. 2015:1-11. [25] Holguin FO, Schaub T. Characterization of microalgal lipid feedstock by direct-infusion FT-ICR mass spectrometry. Algal Research-Biomass Biofuels and Bioproducts. 2013;2:43-50.

[26] Broeckling CD, Huhman DV, Farag MA, Smith JT, May GD, Mendes P, et al. Metabolic profiling of Medicago truncatula cell cultures reveals the effects of biotic and abiotic elicitors on metabolism. J Exp Bot. 2005;56:323-36.

[27] Ponnusamy S, Reddy HK, Muppaneni T, Downes CM, Deng S. Life cycle assessment of biodiesel production from algal bio-crude oils extracted under subcritical water conditions. Bioresource Technoogy (under review). 2014.

[28] Akhtar J, Amin NAS. A review on process conditions for optimum bio-oil yield in hydrothermal liquefaction of biomass. Renewable \& Sustainable Energy Reviews. 2011;15:1615-24.

[29] Toor SS, Reddy H, Deng S, Hoffmann J, Spangsmark D, Madsen LB, et al. Hydrothermal liquefaction of Spirulina and Nannochloropsis salina under subcritical and supercritical water conditions. Bioresource Technology. 2013;131:413-9.

[30] Toor SS, Rosendahl L, Rudolf A. Hydrothermal liquefaction of biomass: A review of subcritical water technologies. Energy. 2011;36:2328-42.

[31] Zhou D, Zhang L, Zhang S, Fu H, Chen J. Hydrothermal Liquefaction of Macroalgae Enteromorpha prolifera to Bio-oil. Energy \& Fuels. 2010;24:4054-61.

[32] Alba LG, Torri C, Samori C, van der Spek J, Fabbri D, Kersten SRA, et al. Hydrothermal Treatment (HIT) of Microalgae: Evaluation of the Process As Conversion Method in an Algae Biorefinery Concept. Energy \& Fuels. 2012;26:642-57.

[33] Yu G, Zhang Y, Schideman L, Funk TL, Wang Z. Hydrothermal liquefaction of low lipid content microalgae into bio-crude oil. Transactions of the Asabe. 2011;54:239-46.

[34] Nedelchev A, Stratiev D, Ivanov A, Stoilov G. BOILING POINT DISTRIBUTION OF CRUDE OILS BASED ON TBP AND ASTM D-86 DISTILLATION DATA. Petroleum \& Coal. 2011;53.

[35] Selvaratnam T, Pegallapati AK, Montelya F, Rodriguez G, Nirmalakhandan N, Van Voorhies W, et al. Evaluation of a thermo-tolerant acidophilic alga, Galdieria sulphuraria, for nutrient removal from urban wastewaters. Bioresource Technology. 2014;156:395-9.

[36] Moscoso JLG, Obeid W, Kumar S, Hatcher PG. Flash Hydrolysis of Microalgae (Scenedesmus sp.) for Protein Extraction and Production of Biofuels Intermediates. The Journal of Supercritical Fluids.

2013;82:183-90.

[37] Brewer CE, Schmidt-Rohr K, Satrio JA, Brown RC. Characterization of Biochar from Fast Pyrolysis and Gasification Systems. Environmental Progress \& Sustainable Energy. 2009;28:386-96.

[38] Sandau E, Sandau P, Pulz O. Heavy metal sorption by microalgae. Acta Biotechnologica. 1996;16:227-35. 
589 [39] Libra JA. Hydrothermal carbonization of biomass residuals: a comparative review of the chemistry, 590 processes and applications of wet and dry pyrolysis. Biofuels. 2011;2:71-106.

591

592 


\section{List of Figures}

594 Figure 1: Product yields of Nannochloropsis sp. and Chlorella sp. at different temperatures of

595 HTL

596 Figure 2: FAME analysis of biocrude oils derived from Nannochloropsis sp. and Chlorella sp.

597 Figure 3: a) Nitrogen recovery from $\mathrm{HTL}$ water fractions, b) $\mathrm{PO}_{4}{ }^{3-}$ recovery from $\mathrm{HTL}$ water

598 fractions

599 Figure 4: Water soluble organic compounds a) Nannochloropsis sp., and b) Chlorella sp.

600

601 List of Tables

602 Table 1. Biochemical properties of algal biomass

603 Table 2. Higher heating values and energy calculations

604

605

606

607

608 

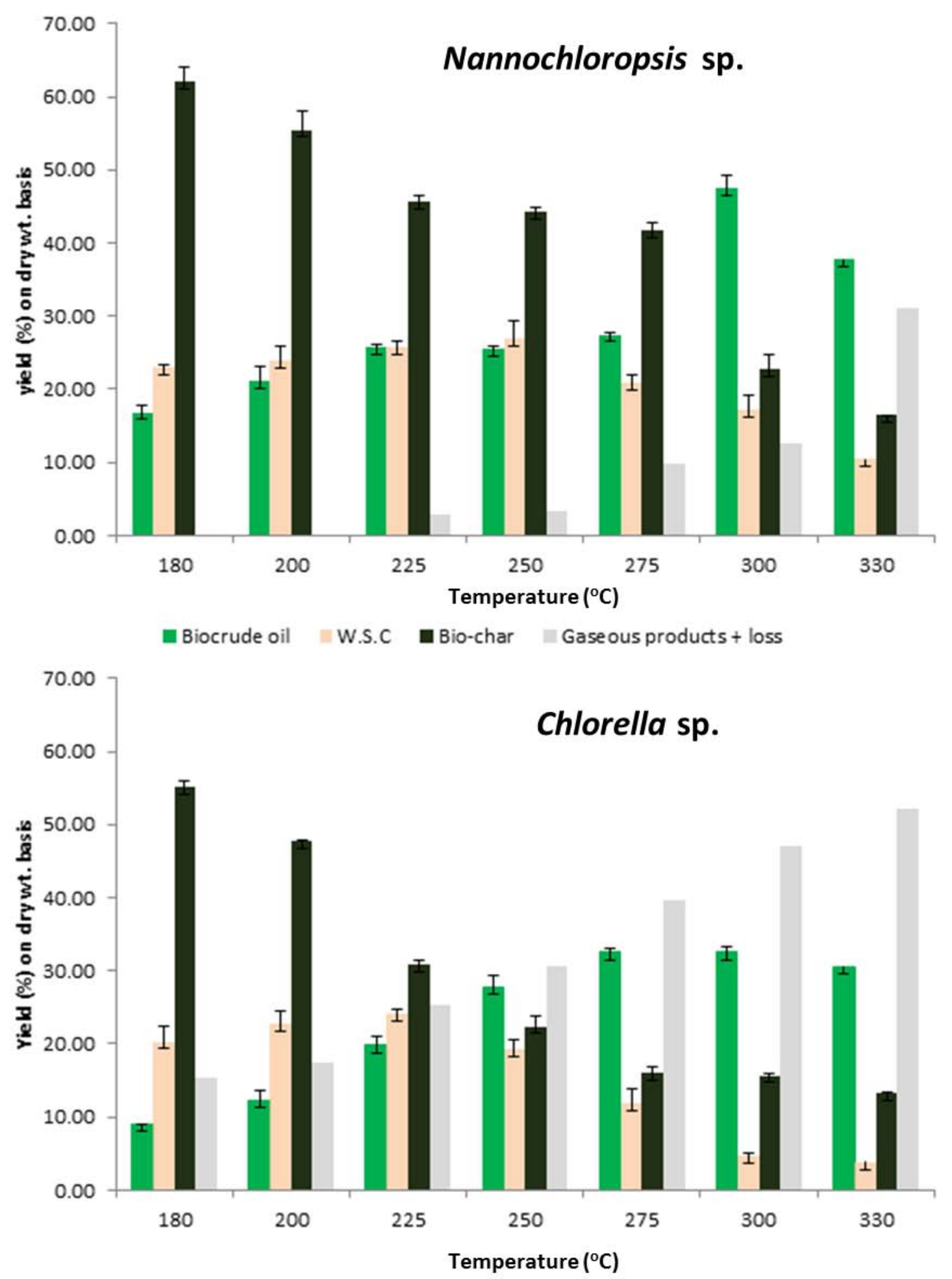

609

610 Figure 1: Product yields of Nannochloropsis sp. and Chlorella sp. at different temperatures of 611 HTL 


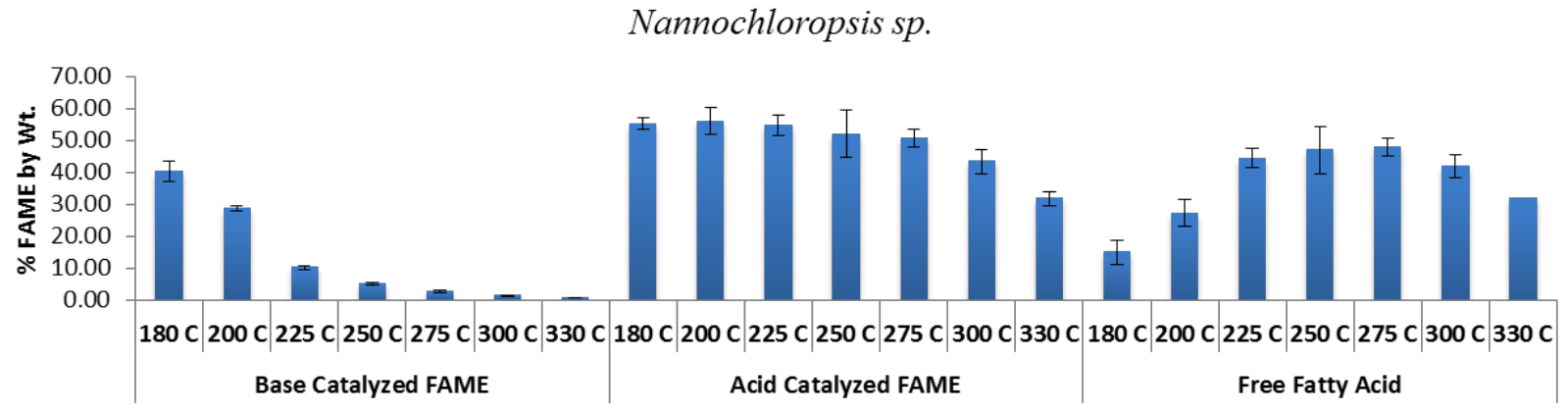

Chlorella sp.

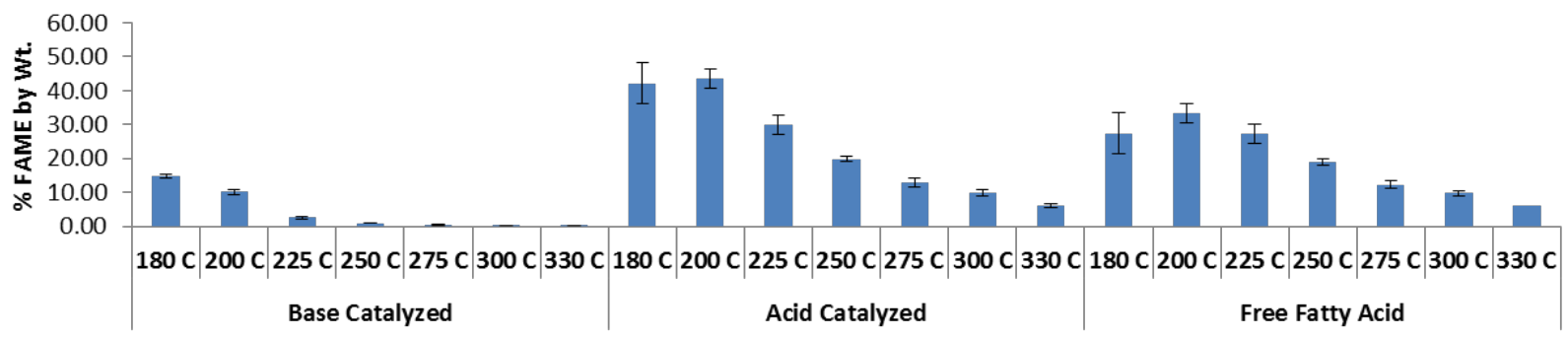

614

Figure 2: FAME analysis of biocrude oils derived from Nannochloropsis sp. and Chlorella sp.

615

616 


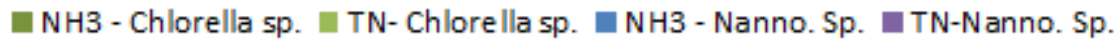
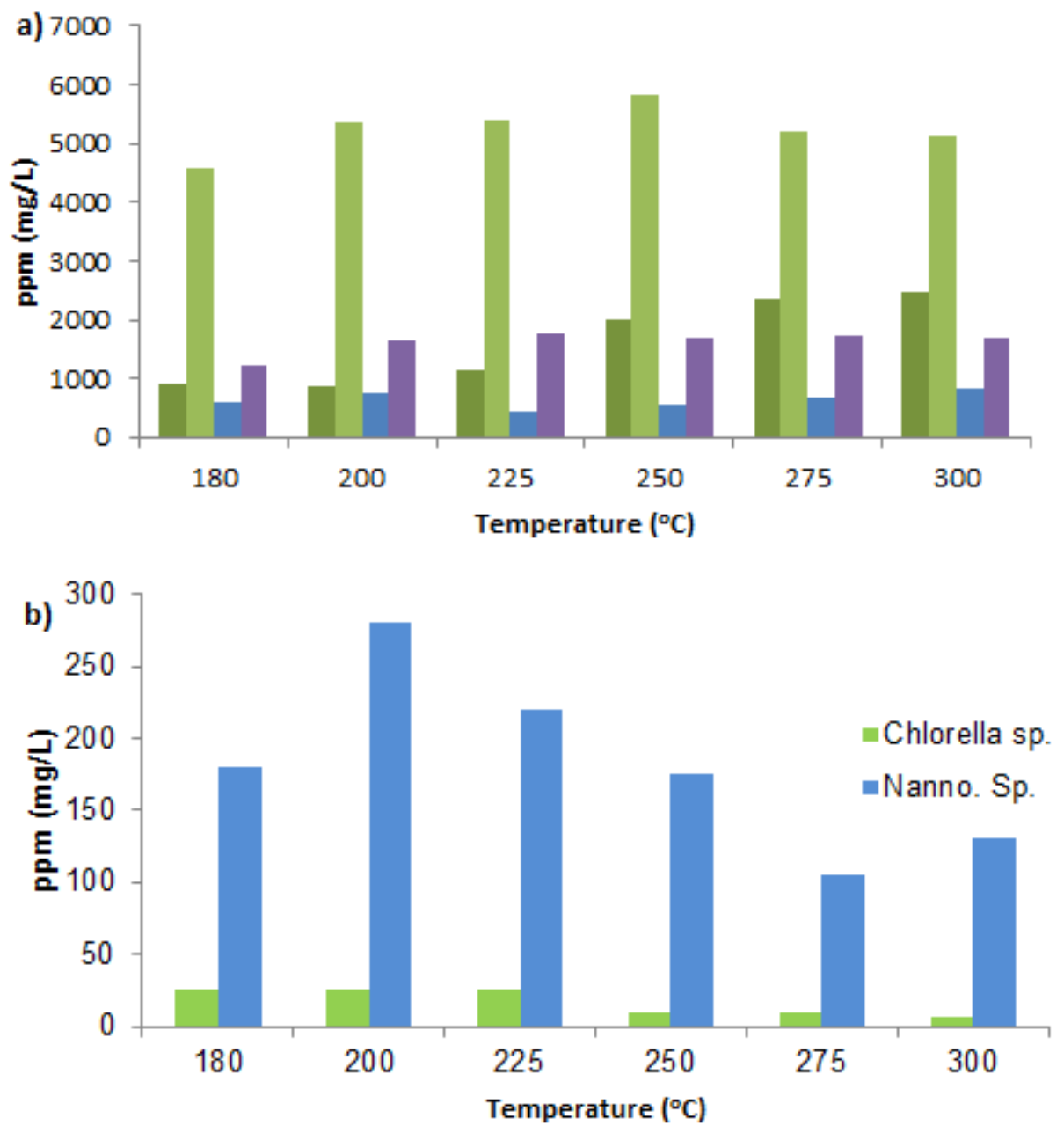

617

618 Figure 3: a) Nitrogen recovery from $\mathrm{HTL}$ water fractions, b) $\mathrm{PO}_{4}{ }^{3-}$ recovery from $\mathrm{HTL}$ water 619 fractions

620 

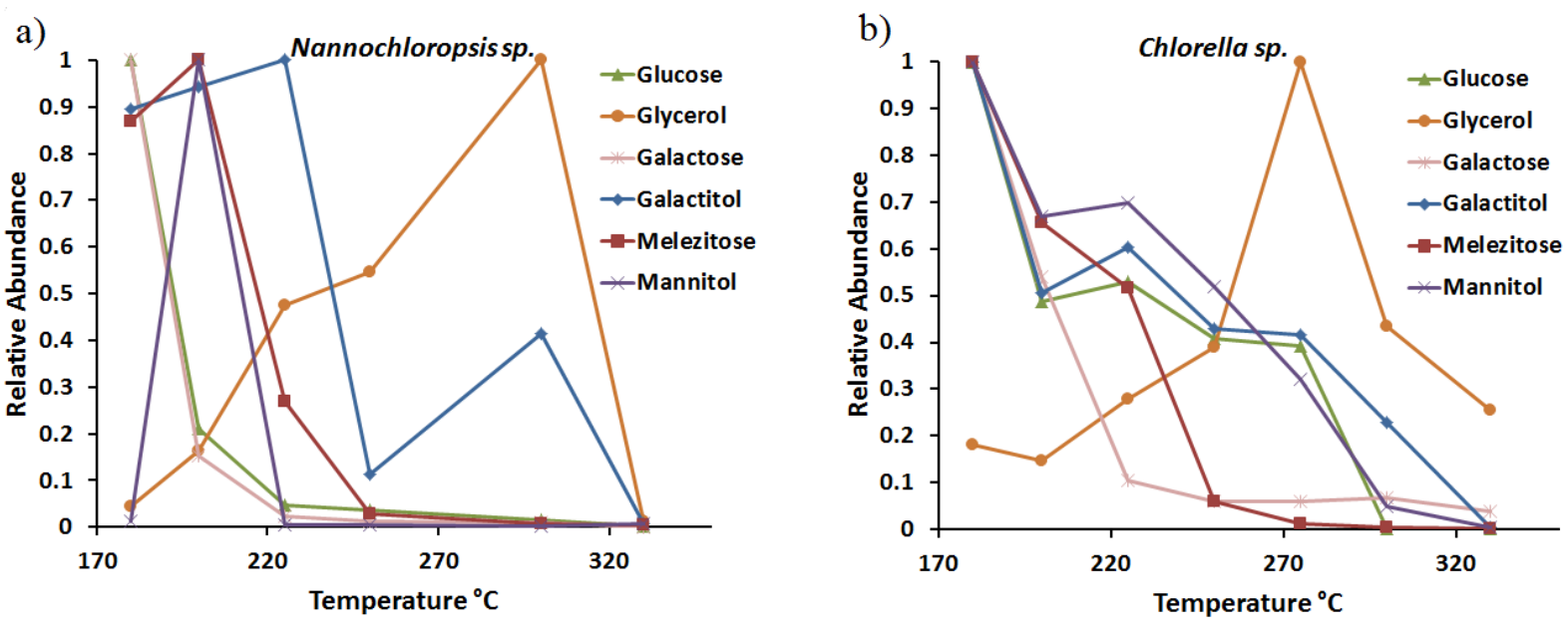

622

623 Figure 4: Water soluble organic compounds a) Nannochloropsis sp., and b) Chlorella sp.

624

625 
626 Table 1. Biochemical properties of algal biomass

\begin{tabular}{lll}
\hline & Nannochloropsissp. & Chlorellasp. \\
\hline Water content (\%) & 79.6 & 74 \\
Ash content (\%) & 7.0 & 2.50 \\
Lipid content (\%) & 21.76 & 10.7 \\
Crude protein (\%) & 14.26 & 44.62 \\
Crude Carbohydrate (\%) & 56.97 & 42.88 \\
HHV (MJ/kg) & 25.0 & 24.3 \\
pH of supernatant water & 7.0 & 7.3 \\
\hline
\end{tabular}

627

628

629 
630 Table 2. Higher heating values and energy calculations

\begin{tabular}{|c|c|c|c|c|c|c|c|c|}
\hline \multirow{10}{*}{ 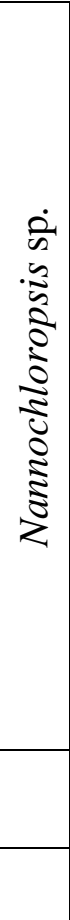 } & Temperature $\left({ }^{\circ} \mathrm{C}\right)$ & 180 & 200 & 225 & 250 & 275 & 300 & 330 \\
\hline & Biocrude oil & & & & & & & \\
\hline & Avg. & 37.92 & 39.19 & 38.06 & 36.76 & 36.83 & 34.60 & 37.37 \\
\hline & S.D & 1.07 & 0.92 & 0.31 & 1.33 & 0.88 & 0.00 & 1.03 \\
\hline & Bio-char & & & & & & & \\
\hline & Avg. & 19.21 & 18.50 & 18.55 & 21.17 & 17.97 & 13.65 & 12.54 \\
\hline & S.D & 0.69 & 0.62 & 0.75 & 1.13 & 1.41 & 0.36 & 2.87 \\
\hline & Energy recovery (\%) & 71.99 & 73.18 & 74.14 & 76.36 & 72.20 & 78.39 & 65.25 \\
\hline & ECR (w/o heat recovery) & 1.15 & 0.98 & 0.93 & 1.08 & 1.09 & 0.73 & 0.93 \\
\hline & ECR (with heat recovery) & 0.68 & 0.57 & 0.53 & 0.61 & 0.61 & 0.41 & 0.51 \\
\hline \multirow{9}{*}{$\begin{array}{l}\dot{0} \\
\frac{0}{\bar{v}} \\
\frac{\tilde{\sigma}}{0}\end{array}$} & Biocrude oil & & & & & & & \\
\hline & Avg. & 36.45 & 37.30 & 37.38 & 36.13 & 34.37 & 37.74 & 36.78 \\
\hline & S.D & 1.01 & 0.44 & 0.66 & 0.44 & 0.85 & 0.17 & 0.49 \\
\hline & Bio-char & & & & & & & \\
\hline & Avg. & 19.82 & 21.23 & 20.73 & 12.69 & 13.63 & 8.62 & 12.05 \\
\hline & S.D & 1.70 & 1.33 & 1.66 & 1.13 & 0.62 & 1.25 & 2.34 \\
\hline & Energy recovery (\%) & 59.3 & 61.3 & 57.5 & 53.7 & 55.7 & 56.8 & 53.9 \\
\hline & ECR (w/o heat recovery) & 2.23 & 1.77 & 1.23 & 1.00 & 0.99 & 0.98 & 1.17 \\
\hline & ECR (with heat recovery) & 1.32 & 1.03 & 0.70 & 0.57 & 0.55 & 0.54 & 0.65 \\
\hline
\end{tabular}


Graphical abstract

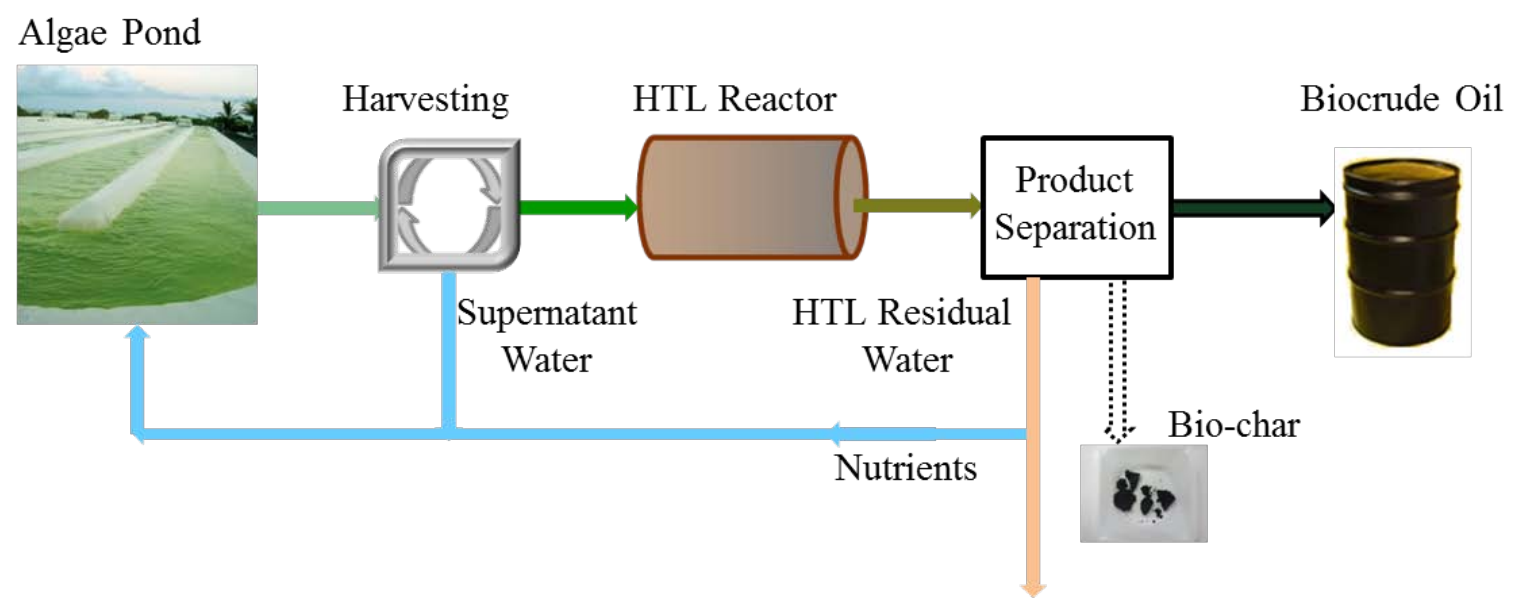

Water Soluble

Organics 